\title{
Kyphoscoliosis and difficult airway management
}

\author{
Kifoskolyoz ve zor havayolu yönetimi
}

\author{
Kemal Tolga Saraçoğlu, ${ }^{1}$ Ömer Baygın, ${ }^{2}$ İbrahim Haluk Kafalı ${ }^{1}$ \\ ${ }^{1}$ Department of Anesthesiology and Reanimation, Medical Faculty of Bilim University, İstanbul, Turkey \\ ${ }^{2}$ Department of Anesthesiology and Reanimation, Medical Faculty ofMarmara University, Istanbul, Turkey
}

\begin{abstract}
Kyphoscoliosis is generally idiopathic and female dominant disease and the prevalence can vary between 0.3-15.3\%. Anesthesia for both adult and pediatric patients with scoliosis can present a variety of challenges, because of some other diseases accompany to scoliosis. One of challenges is airway management. Problems with airway management may be fatal for patients. Basic preparations should be ready for airway management in a situation of unanticipated difficult airway. Besides there should be more than one plan and practitioners. If a strategy fails one should quickly change to another approach. Appropriate equipment beginning from laryngoscopes to a cricothyroid puncture kit should be available regarding practitioner's experience on devices. Extubation of a patient with difficult airway is important as tracheal intubation. Low reintubation rates and patient comfort are the most important issues for the extubation of patients with difficult airway.
\end{abstract}

Keywords: Anesthesia; difficult airway; kyphoscoliosis.

\section{öz}

Kifoskolyoz genel olarak idiopatik ve kadın dominant bir hastalıktır ve prevalansı \%0.3-15.3 arasında değişebilir. Eşlik eden bazı hastalıklar nedeniyle gerek erişkin gerekse de pediatrik skolyoz hastaları için anestezi birçok zorluklar içerebilmektedir. Zorluklardan biri havayolu yönetimidir. Havayolu yönetimiyle ilgili sorunlar hastalar için ölümcül olabilir. Beklenen yada beklenmeyen zor havayolu durumu için temel hazırlıklar hazır bulundurulmalıdır. Bununla birlikte birden fazla plan ve uygulayıcı olmalıdır. Eğer bir stratejide başarısızlık olursa hızlıca diğer yaklaşıma geçilebilmelidir. Uygulayıcının aygıtlar üzerindeki deneyimine göre laringoskoplardan krikoidotomi kitine kadar uygun ekipman bulundurulmalıdır. Bir zor havayolu hastasının ekstübasyonu trakeal entübasyon kadar önemlidir. Düşük reentübasyon oranları ve hasta konforu zor havayoluna sahip hastaların ekstübasyonu için en önemli konulardandır.

Anahtar sözcükler: Anestezi; zor havayolu; kifoskolyoz.

Kyphoscoliosis is generally idiopathic and female dominant disease, associated with the rotation of vertebrae and lumbar spine and deformity of the rib cage. ${ }^{[1-3]}$ Its prevalence can vary between $0.3-15.3 \%$ and has a female:male ratio as $3: 1$ respectively. ${ }^{[4]}$ Scoliosis should be treated at the proper time because especially idiopathic scoliosis has a rapidly progress and may be fatal following the possible complications. ${ }^{[5]}$ Some other types of scoliosis may also have dangerous medical conditions. ${ }^{[6]}$
It is clear that scoliosis has a multifactorial etiology and it is generally presented in idiopathic type. Other types due to congenital, neuromuscular, mesenchymal disorders or trauma take place in classification. . $^{[7,8]}$

Several diseases accompany to scoliosis and anesthesia of adult and pediatric patients with scoliosis can present a variety of challenges. The challenges occur in providing optimal surgical conditions and ensuring adequate oxygenation. ${ }^{[2,5]}$ 
Airway difficulties may be presented in kyphoscoliosis. Besides, airway establishment is most essential for the management of patients. ${ }^{[2,3]}$ Special conditions for the anesthesiologist include anatomical structural differences and the mobility of cervical region. ${ }^{[6,9]}$ It also includes morphological features of airway especially for correctness of the tracheal tube position. ${ }^{[7,10]}$ Prolonged and multiple attempts at laryngoscopy and tracheal intubation are associated with increased morbidity. ${ }^{[1]}$ In this review we aimed to discuss difficult airway management in kyphoscoliosis.

\section{Definition, incidence of the difficult airway}

Severe spinal and thoracic deformities predispose a possible difficult airway. Even when preoperative investigation does not show any signs, visualization of the glottis becomes difficult due to the deviation of epiglottis and larynx. ${ }^{[12]}$ This condition leads to failed intubation in kyphoscoliosis.

The American Society of Anesthesiologists defined a difficult airway as the difficulty of face mask ventilation or difficult tracheal intubation or both for a trained anesthesiologist. ${ }^{[13]}$ Unanticipated difficult airway can cause serious complications and death due to airway trauma ${ }^{[13,14]}$ Difficult airway can be divided to five different categories. ${ }^{[13]}$

1. Difficult mask ventilation is defined as decreasing of arterial oxygen saturation $\left(\mathrm{SpO}_{2}\right)$ due to failure of oxygenation because of anesthesia machine, practitioner or patient factors during the use of face mask. The incidence of difficult mask ventilation cannot be exactly estimated but approximate incidence is $0.9-5 \%{ }^{[15,16]}$ Also when difficult mask ventilation is determined it can be divided into four categories as mild, moderate, severe and impossible. ${ }^{[17]}$ Difficult mask ventilation may be facilitated by several manipulations. ${ }^{[18]}$ Successful mask ventilation is a life saving procedure in case of failed intubation. ${ }^{[19]}$

2. Difficult intubation is defined as multiple attempts for intubation of trachea or more than 10 minutes to be successful. ${ }^{[20]}$ Difficult intubation occurs in $0.13-13 \%$ in population. ${ }^{[15]}$

3. Difficult direct laryngoscopy is defined as despite multiple attempts, visualization of vocal cords with a conventional laryngoscope is not better than Cormack and Lehane [C-L] grades III and IV. ${ }^{[16]}$ The rate of difficult laryngoscopy is between 0.3-20\% even some changes can be applied to definition and patient selection. ${ }^{[21]}$

4. Difficult tracheal intubation is defined as multiple attempts for tracheal intubation. Difficult mask ventilation can accompany to difficult tracheal intubation. ${ }^{[14]}$ Difficult or unsuccessful tracheal intubation is one of the important causes for morbidity and mortality in susceptible patients. ${ }^{[21]}$

5. Failed intubation is defined as providing the airway with tracheal tube fails after multiple attempts. The incidence of failed intubation is $1 / 2,000$ for the elective procedures. ${ }^{[16]}$

Principal adverse outcomes with difficult airway management have a range between airway trauma to the death. ${ }^{[14]}$ When a failed intubation occurs, it can accompany to difficult mask ventilation and in this situation primary concern for the patient becomes to establish ventilation. ${ }^{[19]}$

\section{Difficult direct laryngoscopy}

Direct laryngoscopy is developed for making a line between the practitioner and the patients' laryngeal inlet. ${ }^{[22]}$ When this is not achieved we can mention about difficult direct laryngoscopy. Although prediction of difficult laryngoscopy is not easy, there are some clues. Facial deformities, problems with temporomandibular joint, restricted neck extension, presence of macroglossia are some predictors for difficult laryngoscopy. ${ }^{[14]}$

\section{Why difficult in scoliosis? Scoliosis is a problem with vertebrae}

When scoliosis affects cervical vertebrae, airway management becomes a problem in this situation. ${ }^{[3]}$ Because scoliosis is related with other diseases and symptoms it may affect airway management like in Hurler disease or a short stature. ${ }^{[9,10]}$ The incidence of difficult intubation may exceed $23 \%$ in a Hurler disease patient. ${ }^{[9]}$ In kyphoscoliosis patients and practitioners should be aware of difficult airway management. Limited neck movement is another problem in patients with scoliosis including the cervical vertebrae. ${ }^{[23]}$ Due to the conditions related with alveolar ventilation/perfusion mismatch, patient oxygenation may fail. 
Morphological features of trachea is considered also in airway management because of correct position of endotracheal tube in the trachea. When an anterior approach to scoliosis is performed, one lung ventilation can be necessary and in this case a double lumen tube is introduced to the trachea. ${ }^{[7]}$

\section{American Society of Anesthesiologists difficult airway algorithm}

Problems with airway management have serious adverse affects on patient health status. For this reason before induction of anesthesia a careful airway evaluation is needed. ${ }^{[17]}$ Airway management begins with the history of patient. Previous medical reports and also if patient has a history of previous difficult airway should be accounted. Also patient's acquired or congenital diseases which may affect practitioner's approach the airway should be documented for example temporomandibular ankylosis, Hurler disease, etc. ${ }^{[24]}$

Physical examination should be done whenever possible. Basic preparations should be ready for airway management in a situation of unanticipated difficult airway. Patients should be informed about the risks and the procedures for the control of airway.

Preparations for difficult airway management needs: presence of equipment for management of a difficult airway, notification of patient with a known or suspected difficult airway, provide assistance when a difficult airway is encountered, preanesthetic preoxygenation, and administration of supplemental oxygen during the procedure. ${ }^{[13]}$

Practitioners should have a strategy for the management of difficult airway. Sometimes there should be more than one choice and practitioners could name these strategies as Plan A, B etc. If one strategy fails one should quickly change to another approach. ${ }^{[20]}$

Approaches to difficult airway include awake versus after induction of anesthesia, noninvasive techniques versus invasive techniques, video assisted laryngoscopy and preservation or cessation of spontaneous ventilation. ${ }^{[24]}$

\section{Explanations of the intubating methods in kyphoscoliosis}

Airway management begins with a careful preanesthetic evaluation for difficult laryngoscopy as it is gold standard for intubation. ${ }^{[25]}$ Although current preoperative airway tests to predict true difficulty at laryngoscopy were weak, some clues were present like diabetic patients, body mass index more than $30 \mathrm{~kg} / \mathrm{m}^{2}$ and a mallampati score of at least 2 were associated with difficult laryngoscopy. Even prediction of difficult laryngoscopy is not easy, practitioners should be ready for difficulty in patients with facial deformity, problems with temporomandibular joint, restricted neck extension and the presence of macroglossia.

Basically intubation of a patient needs two devices called introducer and channeller. ${ }^{[18]}$ After Macintosh and Miller developed their direct laryngoscopes for the formation of a line between the practitioner and the patients's laryngeal inlet there are improvements in techniques and equipments for introducers. ${ }^{[26]}$ Intubation methods of a patient have options regarding to route, patient's awakeness and visualization of laryngeal inlet. ${ }^{[24]}$ Intubation of a patient regarding to route are divided into two; nasal versus oral. Although oral route is the usual method for intubation nasal intubation is considered when surgery is concerning in the oral cavity. ${ }^{[26]}$

In patients with difficult airway, practitioners should consider awake intubation before the induction of anesthesia. ${ }^{[27]}$ Anesthesiologist should inform the reasons for awake intubation to the patient. The success rate of awake fiberoptic intubation is between $88-100 \%$. ${ }^{[13]}$

Blind intubation is an another option for tracheal intubation of patients where the larynx cannot be seen on direct laryngoscopy. ${ }^{[28]}$ In this situation practitioner's experience is important for success. In an awake intubation trial, loss of consciousness should be kept in mind.

The technique is an important task for increasing the rate of success for tracheal intubation. Technique includes preparation, introducers, channellers, anesthetic management, correct placement of the endotracheal tube. ${ }^{[24]}$ Although pediatric airway management differs from the airway management in adults due to its significant anatomical and physiological differences, the algorithms of the adult difficult airway management are frequently used. ${ }^{[11]}$ 
Appropriate equipment beginning from laryngoscopes to a cricothyroid puncture kit should be available regarding practitioner's experience on devices. Straight-blade laryngoscopes were found to have an advantage over the curved-blade laryngoscopes in pediatric simulated difficult laryngoscopy models. ${ }^{[1]}$ Preoxygenation with $100 \%$ oxygen for three minutes is recommended for a safe margin. ${ }^{[28]}$

After positioning the patient, introducers for visualization of laryngeal inlet should be inserted. ${ }^{[19]}$ Entire attempts for tracheal intubation should not be much more than 30 seconds. The number of attempts for intubation is not restricted when a failed intubation occurs but the Difficult Airway Society of the United Kingdom suggests that the maximum number of laryngoscopic attempts should be limited to four and before moving to another device the provider has two attempts. ${ }^{[29]}$

Correct placement of endotracheal tube should be confirmed. A malpositioned endotracheal tube can be devastating or an endobronchial intubation results in hypoxemia due to the contralateral lung collapse. ${ }^{[30]}$ Hence monitoring during difficult airway management has great importance. Monitoring includes pulse oximetry and capnography. Listening of breath sounds over both side of thorax and visualization of symmetrical chest expansion may be a confirmation of endotracheal tube placement.

\section{Extubation of the patient with difficult airway}

Tracheal extubation is an important period during emergence from anesthesia and is followed by transferring to postanesthesia care unit. ${ }^{[31]}$ Significant serious patient complications may occur. One third of the complications related to anesthesia occur during anesthesia. ${ }^{[31]}$ Especially cervical spine surgery, patient positioning and the prolonged duration of surgery may cause problems.

The anesthesiologist should need a careful planning for extubation of difficult airway depending on surgery and conditions of the patient. ${ }^{[32-34]}$ This includes planning, preparing and performing of extubation and post-extubation care. Planning of extubation resolved with a risk stratification as low or high risk according to patient's conditions is important. Preparation for extubation needs hemodynamically and neurologically stable patient. ${ }^{[34]}$

For a high risk extubation, anesthesiologist's strategy include laryngeal mask airway placement after the removal of endotracheal tube, extubation slipped over flexible bronchoscope, extubation with an airway exchange catheter or extubation postponed in the intensive care unit. Extubation over a flexible bronchoscope should be considered when an airway pathology exists. An airway exchange catheter maintains access to the airway and facilitates reintubation if necessary. ${ }^{[28]}$ Time for leaving the airway exchange catheter in place have controversial discussions. ${ }^{[33,34]}$ At high risk extubation patients, extubation may be postponed. So patients can be transferred to an intensive care unit.

\section{Conclusions}

Airway management is an important issue in anesthetic procedures. Special conditions like kyphoscoliosis may generate extra disadvantages in airway management which makes it difficult. Preparation in the preoperative period becomes more than an issue in such cases.

\section{Declaration of conflicting interests}

The authors declared no conflicts of interest with respect to the authorship and/or publication of this article.

\section{Funding}

The authors received no financial support for the research and/or authorship of this article.

\section{REFERENCES}

1. Bansal N, Gupta S. Anaesthetic management of a parturient with severe kyphoscoliosis. Kathmandu Univ Med J (KUMJ) 2008;6:379-82.

2. Anand HK, Ambareesha M. Scoliosis and anaesthetic considerations. Indian J Anaesth 2007;51:486-95.

3. Kitayama M, Ohtomo N, Sakai T, Matsuki A. Airway management and rigid spine syndrome. Anesth Analg 1997;84:690-1.

4. Veliath DG, Sharma R, Ranjan R, Kumar CR, Ramachandran T. Parturient with kyphoscoliosis (operated) for cesarean section. J Anaesthesiol Clin Pharmacol 2012;28:124-6.

5. Raw DA, Beattie JK, Hunter JM. Anaesthesia for spinal surgery in adults. Br J Anaesth 2003;91:886-904.

6. Vandenberghe W, Jacobs TF, Plasschaert FS, Willems $J$, Den Blauwen NM, Vereecke HE, et al. Anesthesia 
and perioperative management for a patient with Ullrich syndrome undergoing surgery for scoliosis. Acta Anaesthesiol Belg 2010;61:43-7.

7. Kundra P, Joseph A, Kumar S, Sai Chandran BV. Double-lumen tube for ventilation in severe kyphoscoliosis. J Anesth 2008;22:317-21.

8. Cobb JR: Outline for the study of scoliosis. Instructional course lecture. Am Acad Orthop Surg 1948;5:261.

9. Aucoin S, Vlatten A, Hackmann T. Difficult airway management with the Bonfils fiberscope in a child with Hurler syndrome. Paediatr Anaesth 2009;19:421-2.

10. Gopalakrishna KN, Sriganesh K. Optimal depth of tracheal intubation in severe scoliosis. Chest 2012;142:813-4.

11. Saracoglu KT, Eti Z, Kavas AD, Umuroglu T. Straight video blades are advantageous than curved blades in simulated pediatric difficult intubation. Paediatr Anaesth 2014;24:297-302.

12. A, Novotny Z, Maldini B, Gavranovic Z. Difficult airway management in a polytraumatized patient with osteogenesis imperfecta and multiple congenital spinal and thoracic deformities and severe kyphoscoliosis: case report. Acta Clin Croat 2012;51:489-91.

13. Apfelbaum JL, Hagberg CA, Caplan RA, Blitt CD, Connis RT, Nickinovich DG, et al. Practice guidelines for management of the difficult airway: an updated report by the American Society of Anesthesiologists Task Force on Management of the Difficult Airway. Anesthesiology 2013;118:251-70.

14. Nørskov AK, Rosenstock CV, Wetterslev J, Lundstrøm LH. Incidence of unanticipated difficult airway using an objective airway score versus a standard clinical airway assessment: the DIFFICAIR trial - trial protocol for a cluster randomized clinical trial. Trials 2013;14:347.

15. Shukry M, Hanson RD, Koveleskie JR, Ramadhyani $\mathrm{U}$. Management of the difficult pediatric airway with Shikani Optical Stylet. Paediatr Anaesth 2005;15:342-5.

16. Cook TM, MacDougall-Davis SR. Complications and failure of airway management. $\mathrm{Br} J$ Anaesth 2012;109:68-i85.

17. Healy DW. At higher risk of difficulty is not true difficulty: the challenge of device performance assessment in the difficult airway. Anesthesiology 2012;117:912-3.

18. Etezadi F, Ahangari A, Shokri H, Najafi A, Khajavi MR, Daghigh M, et al. Thyromental height: a new clinical test for prediction of difficult laryngoscopy. Anesth Analg 2013;117:1347-51.

19. Yildiz TS, Solak M, Toker K. The incidence and risk factors of difficult mask ventilation. J Anesth 2005; 19:7-11.

20. Law JA, Broemling N, Cooper RM, Drolet P, Duggan LV, Griesdale DE, et al. The difficult airway with recommendations for management--part 1--difficult tracheal intubation encountered in an unconscious/ induced patient. Can J Anaesth 2013;60:1089-118.

21. Saracoglu KT, Eti Z, Gogus FY. Airtraq optical laryngoscope: advantages and disadvantages. Middle East J Anaesthesiol 2013;22:135-41.

22. Healy DW, Maties O, Hovord D, Kheterpal S. A systematic review of the role of videolaryngoscopy in successful orotracheal intubation. BMC Anesthesiol 2012;12:32.

23. Hagberg CA, Vogt-Harenkamp C, Kamal J. A retrospective analysis of airway management in obese patients at a teaching institution. $\mathrm{J}$ Clin Anesth 2009;21:348-51.

24. Biro P. A proposal for a systematic classification of airway devices similar to the Linnaean taxonomy. Eur J Anaesthesiol 2012;29:499-503.

25. Batra YK, Mathew P. Airway management with endotracheal intubation (including awake intubation and blind intubation. Indian $\mathrm{J}$ Anaesth 2005;49:263-268.

26. De Hert S, Imberger G, Carlisle J, Diemunsch P, Fritsch G, Moppett I, et al. Preoperative evaluation of the adult patient undergoing non-cardiac surgery: guidelines from the European Society of Anaesthesiology. Eur J Anaesthesiol 2011;28:684-722.

27. Asai T. Monitoring during difficult airway management. J Anesth 2014;28:87-93.

28. Law JA, Broemling N, Cooper RM, Drolet $\mathrm{P}$, Duggan LV, Griesdale DE, et al. The difficult airway with recommendations for management--part 2--the anticipated difficult airway. Can $\mathrm{J}$ Anaesth 2013;60:1119-38.

29. Difficult Airway Society Extubation Guidelines Group, Popat M, Mitchell V, Dravid R, Patel A, Swampillai C, Higgs A. Difficult Airway Society Guidelines for the management of tracheal extubation. Anaesthesia 2012;67:318-40.

30. Cavallone LF, Vannucci A. Review article: Extubation of the difficult airway and extubation failure. Anesth Analg 2013;116:368-83.

31. Goranovic T, Maldini B, Markic A, Milic M, Skuric J. Extubation strategy following difficult intubation. Acta Clin Croat 2012;51:499-503.

32. Biro P, Priebe HJ. Staged extubation strategy: is an airway exchange catheter the answer? Anesth Analg 2007;105:1182-5.

33. Cook TM, Woodall N, Frerk C. Major complications of airway management in the UK: results of the Fourth National Audit Project of the Royal College of Anaesthetists and the Difficult Airway Society. Part 1: anaesthesia. Br J Anaesth 2011;106:617-31.

34. Cherng $\mathrm{CH}$, Wong CS, Hsu CH, Ho ST. Airway length in adults: estimation of the optimal endotracheal tube length for orotracheal intubation. J Clin Anesth 2002;14:271-4. 